\title{
A COMISSÃO PARA A CONSTRUÇÃO DA PAZ DAS NAÇõES UNIDAS: COORDENANDO O LOCAL E O GLOBAL?
}

\author{
The Peacebuilding Commission of the United Nations: coordinating the local and the \\ global?
}

\section{Thaíse Kemer ${ }^{1}$}

\section{RESUMO}

O artigo analisa o funcionamento da Comissão para a Construção da Paz das Nações Unidas e discute seu desafio de coordenação com outros atores internacionais e com as realidades locais. Conclui-se que a PBC deve profundar o debate sobre o papel que deseja ter no mundo contemporâneo, pois caso contrário estará fadada a ser somente um novo constructo institucional para ideias pré-concebidas acerca da construção da paz que não contemplam as realidades dos países emergindo de conflitos violentos.

Palavras-Chave: Construção da Paz; Nações Unidas; Ownership Local.

\begin{abstract}
The article analyses the Peacebuilding Commission of the United Nations and discusses the challenge of its coordination with other international actors and with local realities. It is concluded that the PBC should deepen the debate on the role it desires to have in the contemporary world, otherwise it will be only another institutional arrangement for preconceived ideas about peacebuilding that doesn't meet the realities of the countries emerging from violent conflicts.
\end{abstract}

Keywords: Peacebuilding; United Nations; Local Ownership.

\section{INTRODUÇÃO}

O presente artigo apresenta o funcionamento da Comissão para a Construção da $\mathrm{Paz}^{2}$ (PBC) das Nações Unidas e discute o desafio de coordenação de suas atividades com

\footnotetext{
${ }^{1}$ Mestranda em Ciência Política pela Universidade Federal do Paraná, Curitiba, Brasil.

${ }^{2}$ O conceito de construção da paz passou a fazer parte do vocabulário das Nações Unidas a partir de 1992, quando o Secretário Geral das Nações Unidas Boutros-Boutros Gali, estabeleceu, no relatório "Uma Agenda para a Paz" (A/47/277), uma nova taxonomia para as operações de paz no contexto pós-Guerra Fria (PARIS, 2004, p.18). A Agenda definiu cinco instrumentos para que as Nações Unidas pudessem assegurar a paz internacional: (i) Diplomacia Preventiva, voltada para impedir o surgimento de conflitos; (ii) Promoção da Paz (Peacemaking), voltada para trazer as partes hostis para um acordo por meios pacíficos, conforme o Capítulo VI da Carta das Nações Unidas (NAÇÕES UNIDAS, 1945); (iii) Manutenção da Paz (Peacekeeping), voltada para a preservação da paz e o apoio à implementação dos acordos obtidos; (iv) Imposição da Paz (Peace Enforcement), voltada para a restauração da paz internacional, inclusive por meio de medidas coercitivas e militares (NAÇÕES Conjuntura Global, Vol. 4, n. 2, maio/ago., 2015, p. 196-211. 
as de outros atores internacionais com iniciativas para a construção da paz e com as realidades locais dos países emergindo de conflitos violentos. A PBC foi criada conjuntamente com o Escritório de Apoio para a Construção da Paz e com o Fundo para a Construção da Paz, em 2005, e esse conjunto tornou-se conhecido no âmbito das Nações Unidas como a Arquitetura Institucional para a Construção da Paz.

O artigo abordará o tema em duas partes. Na primeira parte, serão discutidas as inovações institucionais trazidas com a criação da Arquitetura para a Construção da Paz, em 2005. Esse estudo terá como foco a análise do funcionamento da PBC e de seus arranjos organizacionais específicos, a saber, o Comitê Organizacional, as Configurações Específicas por País e o Grupo de Trabalho sobre as Lições Aprendidas. Além disso, será analisada sua interação com o Escritório de Apoio e com o Fundo para a Construção da Paz, os quais apoiam a PBC no cumprimento dos propósitos para os quais ela foi concebida.

Na segunda parte, será discutido o relacionamento da PBC tanto com as realidades locais dos países constantes em sua agenda quanto com outras instituições internacionais voltadas para a construção da paz. 0 objetivo dessa seção é analisar duas temáticas fundamentais para a atuação da PBC, quais sejam, o diálogo com as realidades locais e a coordenação dos esforços internacionais para a construção da paz. Esse estudo possibilitará o debate sobre as contribuições trazidas pela PBC para o tratamento da construção da paz, bem como os desafios por ela enfrentados no mundo contemporâneo.

\section{A Comissão para a Construção da Paz (PBC)}

Esta subseção fará um breve histórico do contexto e das motivações das Nações Unidas que levaram à criação da Comissão para a Construção da Paz (doravante PBC), bem como das estruturas a ela associadas: o Fundo para a Construção da Paz (doravante PBF) e o Escritório de Apoio à Construção da Paz (doravante PBSO), em 2005. Além disso, será descrita a sua divisão interna, a qual compreende o Comitê Organizacional, as Configurações Específicas por País e o Grupo de Trabalho sobre as Lições Aprendidas.

A partir do fim da Guerra Fria, os processos de construção da paz passaram a ser vistos, no cenário internacional, como uma estratégia essencial para evitar a recorrência

UNIDAS, 1945, Cap. VII); e (v) Construção da paz no período pós-conflito (Post-Conflict Peacebuilding), voltada para identificar e apoiar estruturas capazes de promover o fortalecimento da paz (A/47/277). 
de conflitos (BELLAMY, 2010, p. 194). Essa percepção trouxe o aumento da complexidade das atividades relacionadas à construção da paz, na medida em que houve a busca por uma abordagem mais abrangente com relação às sociedades emergindo de guerras capaz de possibilitar o tratamento das causas dos conflitos (PARIS, 2009, p.55). Além disso, considerando que, nesse período, diversos atores passaram a atuar sobre os processos de construção da paz - como sociedades civis, governos, organizações nãogovernamentais e organizações internacionais - ampliou-se o entendimento internacional de que seria necessário estimular a coordenação de tais atores (PARIS, 2009, p. 56-57).

Um marco desse debate acerca da necessidade de coordenação dos atores envolvidos nos processos de construção da paz ocorreu por ocasião da realização, em 2004, de um Painel de Especialistas sobre Ameaças, Desafios e Mudanças (A/59/565, 2004). Esse painel propôs, pela primeira vez nas Nações Unidas, a criação de uma Comissão para a Construção da Paz. Essa ideia recebeu grande apoio do Secretário-Geral Koffi Annan, o qual afirmou que havia um gap institucional nas Nações Unidas: a ausência de um sistema capaz de coordenar atores e desenhado para evitar que Estados recaíssem em conflitos e para apoiá-los na transição entre a guerra e a paz (A/59/565, 2004, par. 261; PARIS, 2009, p. 57).

Nesse contexto, foram criados, em 2005, a Comissão (PBC), o Escritório de Apoio e o Fundo para a Construção da Paz, por meio das resoluções 60/180, da Assembleia Geral, e 1645, do Conselho de Segurança (A/RES/60/180; S/RES/1645). Os objetivos da PBC foram assim definidos:

\footnotetext{
a) unir os atores relevantes, aconselhar e propor estratégias integradas para a reconstrução e a construção da paz pós-conflitos;

b) focar a atenção na reconstrução e nos esforços de construção institucional necessários para a recuperação de conflitos e para o apoio ao desenvolvimento de estratégias integradas que permitam estabelecer as bases do desenvolvimento sustentável e;

c) oferecer recomendações e informações para melhorar a coordenação de todos os atores relevantes dentro e fora das Nações Unidas, desenvolvendo melhores práticas (best practices) e apoiando para garantir um financiamento previsível para atividades de recuperação rápida e para estender o período de atenção dedicado à recuperação pósconflito pela comunidade internacional (A/RES/60/180, par. 2) ${ }^{3}$.
}

\footnotetext{
${ }^{3}$ Tradução livre da autora. Original em inglês: “(...) the following shall be the main purposes of the Commission:(a) To bring together all relevant actors to marshal resources and to advise on and propose integrated strategies for post-conflict peacebuilding and recovery; $(b)$ To focus attention on the reconstruction and institution-building efforts necessary for recovery from conflict and to support the development of integrated strategies in order to lay the foundation for sustainable development; (c) To provide recommendations and information to improve the coordination of all relevant actors within and outside the United Nations, to develop Conjuntura Global, Vol. 4, n. 2, maio/ago., 2015, p. 196-211. 
Da leitura de seus objetivos, depreende-se que a Comissão permitiria a maior coordenação entre os diversos atores que compõem os cenários pós-conflito, tanto do ponto de vista do delineamento de estratégias para a construção da paz em tais cenários, quanto do ponto de vista da gestão de recursos de financiamento de projetos. A iniciativa da criação da Comissão foi elogiada por Bellamy (2010), para quem em um cenário internacional com pouco espaço dedicado à reconstrução pós-conflitos, a criação de uma "casa" para a construção da paz teria o potencial de capturar a atenção mundial e trazer maior aporte de recursos para o tema (BELLAMY, 2010, p. 209).

No entanto, divergências sobre o posicionamento e a atuação da PBC no contexto institucional das Nações Unidas foram observadas desde os primórdios do novo arranjo. De fato, Bellamy (idem, p. 200) destaca que a proposta inicial do Painel de Alto Nível sobre Ameaças, Desafio e Mudança era situar a PBC como um órgão subsidiário do Conselho de Segurança, com base no Artigo 29 da Carta das Nações Unidas, o qual afirma: "o Conselho de Segurança poderá estabelecer os órgãos subsidiários que julgar necessários para o desempenho de suas funções" (NAÇÕES UNIDAS, 1945). No entanto, Bellamy (Idem) aponta que essa proposta não foi bem recebida por muitos membros da Assembleia Geral: alguns, como a Índia, por defenderem um órgão mais autônomo que facilitasse o acesso dos países à Comissão, outros, como o Irã, por temerem o aumento da interferência das Nações Unidas nos assuntos domésticos dos Estados.

Com isso, optou-se por situar a PBC na hierarquia das Nações Unidas como um órgão subsidiário de aconselhamento tanto do Conselho de Segurança (S/RES/1645, par. 1) quanto da Assembleia Geral (A/RES/60/180, par. 1). Além disso, o excessivo tempo dedicado a questões procedimentais internas, cerca de um ano, foi criticado por alguns membros da Comissão, como representantes de Austrália, Canadá e Nova Zelândia, para os quais os trabalhos iniciais deveriam ter dedicado maiores esforços no tratamento dos problemas enfrentados pelos países em situação de conflito (PARIS, 2009, p.60) ${ }^{4}$.

Após esse período inicial, a atuação da PBC foi organizada em três arranjos organizacionais, a saber: (i) Comitê Organizacional, que estabelece a agenda de trabalho da PBC e desenvolve estratégias para a a construção da paz; (ii) Configurações

best practices, to help to ensure predictable financing for early recovery activities and to extend the period of attention given by the international community to postconflict recovery." (A/RES/60/180, par. 2).

${ }^{4}$ Maiores informações sobre os extensos debates travados nas Nações Unidas acerca da criação da PBC podem ser obtidos em: Neves (2009); Rodrigues (2013) e em Jenkins (2013).

Conjuntura Global, Vol. 4, n. 2, maio/ago., 2015, p. 196-211. 
Específicas por País (em inglês Country Specific Configurations, doravante CSC), que realiza reuniões específicas para cada país presente na agenda de trabalho da PBC e (iii) Grupo de Trabalho sobre as Lições Aprendidas (em inglês Working Group on Lessons Learned, doravante WGLL), cujo objetivo é extrair lições das experiências nacionais e internacionais de construção da paz, confome exposto na :

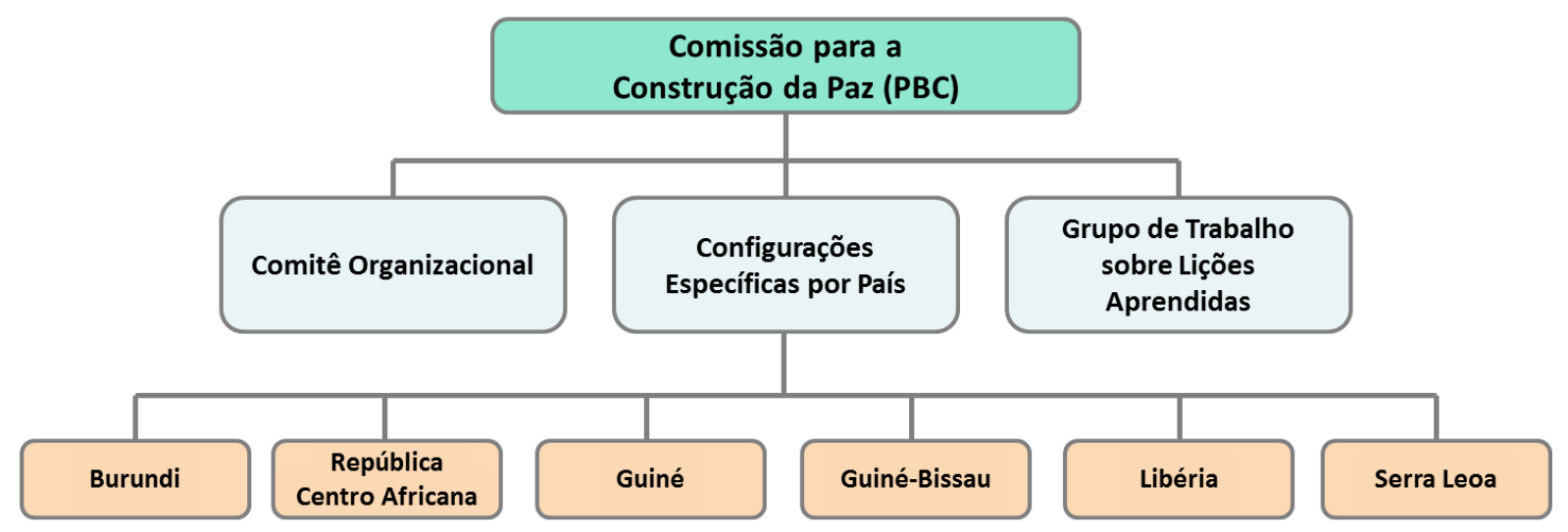

Figura 1: Estrutura da PBC.

Fonte: Rodrigues (2011, p. 7) com adaptações da autora.

À esquerda da Erro! Fonte de referência não encontrada.1 está o Comitê Organizacional, que tem o objetivo de estabelecer a agenda de trabalho da PBC e de desenvolver estratégias para a construção da paz (PBSO, 2015). 0 Comitê é composto por 31 membros, que possuem mandatos renováveis de dois anos e tomam decisões por consenso (A/RES/60/180; par.18). Os membros do Comitê estão distribuídos da seguinte forma: (a) sete membros do Conselho de Segurança, incluindo os cinco membros permanentes ${ }^{5}$; (b) sete membros do Conselho Econômico e Social; (c) sete membros eleitos pela Assembleia Geral; (d) os cinco maiores contribuintes para o orçamento das Nações Unidas; (e) os cinco maiores contribuintes de agentes militares e civis para as Nações Unidas (A/RES/60/180; par.7). Além desses atores, devem estar presentes em todas as reuniões representantes da União Europeia, do Banco Mundial, do

\footnotetext{
${ }^{5}$ O Conselho de Segurança conta com 15 membros, sendo 5 permanentes e 10 rotativos. Neves (2009, p. 141 145) recorda que as resoluções 60/180 e 1645 (2005) haviam previsto que sete membros do Conselho de Segurança fariam parte da Comissão, e que, entre os sete, seriam incluídos membros permanentes. Posteriormente, O Conselho de Segurança aprovou a resolução 1646 (2005), que decidiu pela inclusão de todos os cinco membros permanentes na PBC, o que reduziu a participação dos membros rotativos nessa Comissão. Dessa forma, a PBC, endossada por diversos países que desejavam uma ampla reforma das Nações Unidas, como o Brasil, terminou por corroborar a estrutura existente de poder (NEVES, 2009, p. 141-145; S/RES/1646, 2005, par. 1).

Conjuntura Global, Vol. 4, n. 2, maio/ago., 2015, p. 196-211. 
Fundo Monetário Internacional e da Organização para a Cooperação Islâmica (PBSO, 2015). ${ }^{6}$

Ao centro da Figura 1 estão são as Configurações Específicas por País (CSCs) ${ }^{7}$, que são reuniões específicas para cada país presente na agenda de trabalho da PBC. As CSCs têm sua composição variável em função do contexto do Estado em questão. Em 2015, seis países constam da Agenda da PBC - e, portanto, contam com Configurações Específicas, a saber: Burundi, Serra Leoa, Guiné-Bissau, República Centro-Africana, Guiné Equatorial e Libéria.

As CSCs devem reunir, além dos membros do Comitê Organizacional, representantes: (a) do país em consideração; (b) dos países e organizações engajados nos esforços de apoio e no diálogo político; (c) dos principais financiadores e contribuintes de tropas das Nações Unidas; (d) das Nações Unidas relativamente ao país em questão; (e) das instituições financeiras regionais e internacionais (A/RES/60/180). De acordo com as resoluções 60/180 e 1645 (2005), um país pode ser incluído na agenda da PBC - e, portanto, torna-se objeto de uma CSC - mediante a solicitação de aconselhamento feita por um dos seguintes atores: (a) Conselho de Segurança; (b) Comitê Econômico e Social (ECOSOC) ou Assembleia Geral, com o consentimento do Estado-Membro em questão; (c) Estados-Membros, em circunstâncias excepcionais nas quais o Estado esteja na iminência de entrar em conflito e não esteja na agenda do Conselho de Segurança e; (d) Secretário-Geral (A/RES/60/180, 2005, par. 12). Os países que podem solicitar o apoio da PBC, por sua vez, devem estar emergindo de conflitos, ou, ainda, terem concluído um acordo de paz. Além disso, segundo as Nações Unidas, o encaminhamento de um país contra a vontade de seu governo constitui uma ocorrência “improvável" (PBC, 2015).

À direita da Figura 1 está o Grupo de Trabalho sobre as Lições Aprendidas (WGLL) ${ }^{8}$. 0 objetivo do WGLL é garantir que o engajamento da PBC com os países presentes em sua agenda seja pautado pelo conhecimento das "melhores práticas", tanto das Nações Unidas quanto de outras organizações, em processos de construção da paz. Para tanto, é previsto que o WGLL seja apoiado pelo PBSO, por meio do aporte de novas

\footnotetext{
${ }^{6}$ A lista atualizada dos países membros da Comissão e das Configurações específicas por país pode ser obtida em (PBSO, 2015).

${ }^{7} \mathrm{O}$ acrônimo CSC vem do original em inglês Counter Specific Configuration.

${ }^{8} \mathrm{O}$ acrônimo WGLL vem do original em inglês Working Group on Lessins Learned.

Conjuntura Global, Vol. 4, n. 2, maio/ago., 2015, p. 196-211. 
ideias, de materiais de base (briefings) e de apoio programático (JENKINS, 2013, p.4748; WGLL, 2015).

O WGLL define-se como uma plataforma informal cujo objetivo é ampliar o diálogo em questões de relevância para os países presentes na agenda da PBC. O WGLL conta com um líder, o qual é eleito entre os 31 membros da PBC (JENKINS, 2013, p.4748), e não tem um número delimitado de membros, na medida em que é aberto a todos os Estados-Membros, entidades das Nações Unidas, doadores e representantes da sociedade civil (WGLL, 2010, p. 5). Com essa configuração, o WGLL reune-se periodicamente para discutir itens que sejam tanto de de interesse dos membros da PBC quanto questões de interesse comum às diferentes CSCs (JENKINS, 2013, p.47). Entre 2007 e 2014, o WGLL reuniu-se mais de trinta vezes e tratou de temas diversos, de questões relativas aos contextos nacionais à coordenação entre a PBC e as demais agências das Nações Unidas (WGLL, 2015). Dessa forma, explanada a estrutura geral da PBC, a seção seguinte discutirá um desafio central para o arranjo das Nações Unidas para a construção da paz: a coordenação da Comissão com atores locais dos países emergindo de conflitos violentos e com atores internacionais atuantes em processos de construção da paz.

\section{A PBC e os desafios da nova institucionalização da paz liberal}

A presente seção discute a relação da PBC tanto com as realidades locais dos países constantes em sua agenda quanto com outras instituições internacionais voltadas para a construção da paz, inclusive os demais integrantes da Arquitetura para a Construção da Paz de 2005. Na visão de De Conning (2008, p. 97) sem que haja a coordenação dos agentes atuantes na construção da paz, e sem que haja a apropriação nacional (national ownership) - conceito que será debatido na presente seção -, é inconcebível que um sistema que vise a construção da paz seja viável. Dessa forma, a análise é relevante por abranger temáticas fundamentais para a atuação da PBC, quais sejam, o diálogo com as realidades locais e a coordenação dos esforços internacionais para a construção da paz.

Para tanto, em primeiro lugar, serão evidenciados os pressupostos teóricos que norteiam a atuação da PBC. Em seguida, discutir-se-ão as implicações de tais pressupostos para a implementação da ideia de apropriação nacional, segundo a qual os 
países devem assumir um papel central no desenvolvimento dos processos de construção da paz. Finalmente, discute-se a interação da PBC com as demais instituições internacionais voltadas à construção da paz.

No que concerne aos pressupostos teóricos da PBC, destaca-se, em primeiro lugar, a visão de Rodrigues (2013, p. 234), segundo o qual a PBC enquadra-se no paradigma da paz democrática e liberal, na medida em que "replica e reforça" aspectos centrais desta. Nesse sentido, ao atuar em Nova Iorque, ser informada precipuamente por seus Estados-Membros e nortear suas iniciativas em função, principalmente, das preocupações do Secretariado, a PBC evidencia sua natureza "top-down" e, assim, distancia-se das populações locais. Em consequência desse contexto, as estratégias elaboradas pela PBC refletem a paz democrática e liberal como o paradigma central para a construção da paz no contexto das Nações Unidas (idem, p. 247-248). Para ilustrar esse argumento, Rodrigues (2013) analisou os documentos estratégicos ${ }^{9}$ para a construção da paz elaborados pela PBC para os seis países presentes em sua agenda. Com base nessa análise, o autor concluiu que em todos os documentos constavam prioridades associadas à paz democrática e liberal, tais como a realização de eleições, o fortalecimento do Estado de Direito e a realização de reformas administrativas e no setor de segurança (idem, p. 251).

Em decorrência desse enquadramento da PBC ao paradigma da paz democrática e liberal, é possível afirmar que existe uma diferença entre o discurso e a prática da PBC no contexto das interações que esta mantém com as realidades nacionais. Conforme Stamnes (2010, p. 12), apesar de a "local ownership" ser enfatizada na ONU, essa área deve ser aprimorada. De fato, essa argumentação é comprovada por diversas evidências empíricas no contexto da PBC e de sua interação com os países. Nesse sentido, a Revisão da Arquitetura da Construção da Paz das Nações Unidas ${ }^{10}$, realizada em 2010, enfatizou a importância atribuída pela PBC à noção de apropriação nacional (national ownership),

\footnotetext{
${ }^{9}$ Esses documentos são os instrumentos de engajamento da PBC com relação aos países presentes em sua agenda: (a) Quadro Normativo Estratégico para a Construção da Paz no Burundi, (b) Quadro Normativo de Cooperação para a Construção da Paz em Serra Leoa, (c) Quadro Normativo Estratégico para a Construção da Paz na Guiné-Bissau, (d) Quadro Normativo Estratégico para a Construção da Paz na República Centro Africana (2009-2011), (e) Documento de Compromissos Mútuos sobre a Construção da Paz na Libéria, (f) Documento de Compromissos Mútuos sobre a Construção da Paz na Guiné entre o Governo da Guiné e a Comissão para a Construção da Paz (RODRIGUES, 2013, p. 251).

${ }^{10}$ Essa Revisão estava prevista nas resoluções fundadoras da Arquitetura para a Construção da Paz criada em 2005 (A/60/180- S/RES/1645, 2005, par. 27), e deveria ocorrer cinco anos após a entrada em vigor das mesmas. Nesse processo, após consultas aos membros das Nações Unidas e visitas aos países da agenda da Comissão, foi divulgado, em Julho de 2010, o relatório intitulado "Revisão da Arquitetura das Nações Unidas para a Construção da Paz" (A/64/868, 2010).

Conjuntura Global, Vol. 4, n. 2, maio/ago., 2015, p. 196-211. 
no sentido que os países deveriam participar ativamente dos processos de construção da paz (A/64/868, par. 17-19). No entanto, a Revisão apontou que a PBC não foi capaz de gerar esse sentido de apropriação nacional em áreas críticas como a de planejamento, a qual deveria contar com a participação dos países desde a sua formulação (A/64/868, par. 49-50). Além disso, durante as entrevistas da Revisão, abordou-se o fato de que as preocupações e a visão nos países podem diferir significativamente da perspectiva dos escritórios de Nova Iorque. Em outras palavras, ainda que o planejamento estratégico pareça adequado na visão de Nova Iorque, pode constituir um fardo administrativo para as administrações já frágeis e sobrecarregadas de determinados países (A/64/868, par. 31).

Em particular, de acordo com a Revisão de 2010, nos casos de Guiné-Bissau e da República Centro Africana, o delineamento de estrátegias de construção da paz constituíram processos prolongados, nos quais a duplicação de estratégias previamente existentes para a redução da pobreza constituíram motivo de frustração para os atores em campo (idem, par. 40). Esses exemplos remetem ao conceito de "paz virtual", discutido por Richmond (2007, p. 178) e por Richmond \& Franks (2008, p. 198) segundo o qual as diferenças entre as percepções interna e externa do conflito sobre o conflito pode acarretar a produção de instituições vazias, as quais não atendem às necessidades básicas das populações locais.

Para Stamnes (2014, p. 13) esse descasamento entre as práticas da PBC e as realidades locais origina-se no viés liberal empregado pela PBC para a disseminação de suas práticas. A construção da paz contemporânea, nesse sentido, é baseada na assunção de que a paz liberal tem validade universal (idem, p. 26; MAC GINTY \& RICHMOND, 2013, p. 772). Isso implica aceitar que a criação de democracias liberais e de mercado seria a única alternativa para os países emergindo de situações de conflitos violentos, e conformaria o único meio de promoção da paz. Na visão de Stamnes (2010), essa presunção de universalidade torna a implementação das reformas e programas parecer "senso comum", excluindo, dessa forma, a possibilidade de operacionalizações alternativas (idem, p. 26). Dessa forma, o autor argumenta que a busca pelo ownership local significa, para a ONU, uma forma de legitimar sua ação, e que a agenda a "ser apropriada" pelas realidades locais é, em última análise, definida externamente (idem, p. 13). 
Em linha com essa argumentação, Sending (2009, p.8) defende que o conteúdo das ações de construção da paz são definidos com base em princípios liberais que estipulam como as sociedades emergindo de conflitos deveriam ser, idealmente, organizadas e governadas. Com isso, o conhecimento técnico dos agentes internacionais que atuam na temática da construção da paz, os "peacebuilders", ganha precedência sobre os conhecimentos específicos associados às realidades nacionais (idem, p. 12). Assim, o conhecimento sobre o contexto geográfico, político, econômico e social é considerado um "meio" para atingir um "fim" que é pré-determinado: promover ajustes na forma pela qual será implementada uma agenda liberal e pré-definida de construção da paz (idem, p. 13-14)

O segundo momento da análise aborda a necessidade de aprimorar a coordenação da PBC no contexto da estrutura institucional das Nações Unidas para a construção da paz. De Coning (2008, p. 92) entende que coordenação é a atividade por meio da qual se busca a coerência. Por sua vez, o autor define coerência como o esforço que permite o direcionamento de atividades em áreas distintas, como nas dimensões social, política e econômica, para atingir a uma finalidade comum, no caso, a construção da paz (idem, p. 91).

Com base nessa definição, é relevante destacar as conclusões da Revisão da Arquitetura Institucional das Nações Unidas de 2010 (A/64/868), a qual destacou que a PBC foi desenhada para exercer um papel de coordenação entre os diversos atores envolvidos em contextos de construção da paz. No entanto, o mesmo relatório apontou que, na prática, a melhoria da coordenação entre tais atores permanecia um desafio a ser enfrentado pela PBC. Como exemplos dessa falta de coordenação, destacou-se que: "existe uma visão amplamente compartilhada de que a Assembleia Geral teve pouca participação nas atividades da Comissão e que uma relação mais estruturada e interativa é necessária" (A/64/868, par. 115) ${ }^{11}$. 0 mesmo ocorreria com o Conselho Econômico e Social, o qual foi encorajado a incluir o tema da construção da paz em suas reuniões atuais como forma de facilitar o diálogo com a PBC (idem, par. 122). Na mesma linha argumentativa, a Revisão de 2010 recomendou que a PBC deveria melhorar sua coordenação tanto com o Fundo para a Construção da Paz quanto com o Escritório de Apoio (idem, par. 164).

\footnotetext{
${ }^{11}$ Tradução da autora. Original em inglês: “... there is a widely shared view that the General Assembly has had insufficient weight in the activities of the Commission and that more structured and interactive relations are needed". (A/64/868, par. 115). 
Na visão de Paris (2009, p. 73) e de Bellamy (2010, p. 202), uma das características que minaram a habilidade de a PBC exercer a coordenação de atores foi justamente o fato de ela não ter autoridade formal nem mesmo sobre outras estruturas no contexto das Nações Unidas. Nesse sentido, a PBC somente pode exercer sua função de aconselhamento quando houver um consenso entre seus membros, algo que pode restringir sua atuação para a construção da paz.

No entanto, o debate acadêmico sobre o tema evidencia que a questão de coordenação é complexa e que ultrapassa a existência do elemento de autoridade formal de uma instância internacional da construção da paz sobre as demais. Nesse sentido, Roland Paris (2009) aponta que a questão da coordenação ultrapassa a redefinição dos problemas em termos procedimentais e exige a compreensão de questões complexas, como quais estratégias devem ser adotadas para a construção da paz, e como deve ser a relação entre as organizações internacionais e as populações locais em tais processos (PARIS, 2009, p. 58). Nesse sentido, o autor analisa o ambiente da cooperação internacional para a construção da paz como um cenário próximo à estrutura de redes (networks), na qual atores cooperam a partir de localidades e por meio de abordagens distintas, para a construção da paz.

A estrutura de redes pode trazer vantagens e desvantagens para a coordenação da construção da paz: aquelas, ao permitir que atores distintos possam buscar estratégias inovadoras para lidar com as complexidades dos cenários pós-conflito, e estas, ao dificultar os esforços de coordenação, para os quais pode ser necessária alguma forma de hierarquização (PARIS, 2009, p.60-63). Dessa forma, o autor diz que é necessário que a PBC encontre uma forma de equilíbrio, que seja capaz, ao mesmo tempo, de ampliar a troca de informações e a comunicação e, ao mesmo tempo, não trazer consigo uma estrutura hierárquica sobrecarregada (PARIS, 2009, p.64).

Como um complemento à análise de Roland Paris, De Coning (2008, p. 91) reconhece o conjunto das instituições internacionais para a construção da paz como um sistema complexo, no qual é possível que a coerência entre os peacebuilders nunca seja atingida. Dessa forma, o autor argumenta que seria possível identificar graus de coerência entre os atores envolvidos nos processos de construção da paz.

Ainda que não esteja claro qual seria o resultado ótimo desse "processo" de coordenação de peacebuilders pela $\mathrm{PBC}$, claro está que permanecem questionamentos quanto à coordenação atualmente promovida por essa Comissão. Tais questionamentos Conjuntura Global, Vol. 4, n. 2, maio/ago., 2015, p. 196-211. 
envolvem: (1) a coordenação da PBC com o sistema institucional das Nações Unidas e; (2) a coordenação da PBC com com peacebuilders de organizações extra-ONU.

No que concerne ao contexto das Nações Unidas, embora a PBC constitua um novo arranjo institucional para a construção da paz, para Hearns et al. (2014, p. 5) esse arranjo não trouxe uma forma mais institucionalizada de trabalho para as Nações Unidas. Nesse sentido, para para esses autores, a forma de atuação da PBC depende muito mais da boa vontade e do comprometimento pessoal dos líderes das Configurações Específicas por País (CSC) do que de uma forma mais institucionalizada de trabalho da PBC com as instituições das Nações Unidas e com os países em processos de construção da paz (idem). De fato, de acordo com a análise da organização sem fins lucrativos Security Council Report (2013, p. 6) os líderes das sucessivas configurações para Serra Leoa parecem ter desenvolvido boas relações de trabalho com o Escritório Integrado para a a Construção da Paz de Serra Leoa (UNIPSIL). Ao contrário, no caso da República Centro Africana, o líder da CSC deixou o cargo em junho de 2012, após discordâncias sobre o agendamento de uma conferência de doadores. Essas dinâmicas, segundo o Security Council Report, afetaram diretamente a atuação da PBC em tais países, de maneira que o impacto das relações interpessoais dos líderes das CSCs exerce um papel considerável no contexto da gestão das atividades da PBC (idem).

Além disso, Hearns et al. (2014, p. 8) destacam que relação entre a PBC e o Conselho de Segurança é precária, uma vez, segundo os autores, alguns membros do Conselho não atribuem importância ao aconselhamento oferecido pela PBC em seus processos de construção da paz. De fato, o Security Council Report (2013, p. 6-7) afirmou que a relação entre a PBC e o Conselho de Segurança foi "pouco dinâmica", e que essa relação foi objeto de debates durante a presidência da Colômbia da PBC, em Julho de 2012. Naquela ocasião, discutiram-se formas de aprimorar a sinergia entre os órgãos, e sugeriu-se que a PBC poderia trazer maior proximidade entre o Conselho de Segurança e as realidades locais, fornecendo informações sobre a apropriação nacional dos países e da coerência dos esforços de construção da paz nos países em sua agenda (idem).

A despeito dessa sugestão, a PBC tem problemas tanto para dialogar com as realidades locais, conforme exposto nesta seção, quanto para promover a coerência de suas atividades com outros peacebuilders que atuam nos países na agenda da PBC. De fato, Hearns et al (2014, p. 8), analisou a PBC por meio de entrevistas com membros da PBC, dos países constantes em sua agenda, do Conselho de Segurança e outros 
representantes das Nações Unidas. Segundo o autor, os atores envolvidos em processos de construção da paz ainda continuam com uma visão pouco clara dos objetivos e do impacto da PBC. Esse déficit na comunicação da PBC também foi reconhecido pelas Nações Unidas (A/64/868, par. 65), segundo a qual essa falha fez com que a PBC fosse, por vezes, entendida como um mero meio de acesso aos financiamentos oriundos do PBF (idem).

Dessa forma, conclui-se que a interação da PBC tanto com a realidade dos países presentes em sua agenda quanto com os demais organismos que atuam para a construção da paz internacional demonstram a dimensão da complexidade que permeia os processos de construção da paz contemporâneos. A criação de um novo organismo, nesse contexto, buscou solucionar problemas como a "falta de coordenação" entre peacebuilders e a busca de estratégias integradas para a construção da paz. No entanto, a falta de questionamentos mais profundos sobre tais temáticas fez com que a atuação da PBC seja, ela própria, protagonista dos desafios para os quais foi criada. Em outras palavras, a PBC enfrenta, na atualidade, tanto o desafio de aprimorar sua coordenação com outros peacebuilders quanto o desafio de dialogar com as realidades locais desafios que, paradoxalmente, motivaram a criação da Comissão.

\section{Considerações finais}

$\mathrm{O}$ artigo analisou a arquitetura institucional das Nações Unidas para a construção da paz, com o intuito de compreender o papel da PBC nesse contexto institucional. A PBC foi criada com vistas a buscar a melhor coordenação entre atores nacionais e internacionais envolvidos em processos de construção da paz, assim como aproximar-se das realidades nacionais e buscar trazer recursos para tais realidades. 0 Fundo buscaria catalisar tais recursos, e assegurar uma gestão adequada entre coordenadores e países que fosse capaz de proporcionar a esses países os meios necessários para tornar viáveis seus processos de cosntrução da paz. O Escritório de Apoio, por sua vez, promoveria o apoio à PBC e ao PBC, de forma a promover a coordenação desses entes.

No entanto, verificou-se, no presente artigo, que a PBC padece dos mesmos desafios que motivaram a sua criação. Por um lado, a PBC tem o desafio de aprimorar sua coordenação tanto com outros órgãos e departamentos quanto com outros peacebuilders internacionais. Essa tarefa é dificultada em um cenário internacional de 
crescente complexidade, no qual os atores presentes nos processos de construção da paz são oriundos de diversas organizações e países, o que confere um caráter inerentemente descentralizado a tais processos. Por outro, a PBC enfrenta o desafio de aproximar-se das realidades locais e de promover o local ownership. Ao que indica a literatura analisada, existem indícios de que essa dificuldade seja resultado do viés de construção da paz liberal operacionalizado pela PBC. Assim, nos termos de Stamnes (2010), ao assumir que esse viés pode ser universalmente utilizado, resta pouco espaço para a incorporação de visões alternativas da promoção da paz, como a visão das realidades locais. Consequentemente, forma-se um terreno propício à implementação de uma paz virtual (RICHMOND, 2007, p. 178; RICHMOND \& FRANKS, 2008, p. 198).

Dessa forma, a nova arquitetura institucional das Nações Unidas traz, em seu bojo, parte dos problemas enfrentados pela arquitetura institucional precedente das Nações Unidas. Assim, sem que a PBC traga um debate mais amplo sobre o papel que essa instituição deseja ter no mundo contemporâneo, ela está fadada a ser somente um novo constructo institucional para ideias pré-concebidas acerca da construção da paz e das realidades dos países que dela necessitam.

\section{REFERÊNCIAS}

BELLAMY, Alex J. (2010). The institutionalisation of peacebuilding: what role for the Un Peacebuilding Commission? In: RICHMOND, Oliver. Peacebuilding: critical developments and approaches. Nova Iorque. Palgrave Macmillan. 2010.

DE CONING, Cedric. The Coherence Dilemma in Peacebuilding and Post-Conflict Reconstruction Systems. African Journal on Conflict Resolution. p. 85-110. Volume 8, Número 3, 2008.

HEARN, Sara; BUJONES, Alejandra Kubitschek; KUGEL, Alischa. The United Nations "Peacebuilding Architecture": Past, Present and Future. NYU Center on International Cooperation (CIC) Maio de 2014. Disponível em: <http://cic.nyu.edu/sites/default/files/un_peace_architecture.pdf> Acesso em: 11 de Fevereiro de 2015.

JENKINS, Rob. (2013). Peacebuilding. From Concept to Commission. New York: Routledge.

MAC GINTY, Roger; RICHMOND, Oliver P (2013): The Local Turn in Peace Building: a critical agenda for peace. Third World Quarterly, 34:5, 763-783

NAÇÕES UNIDAS (1945). Carta das Nações Unidas e Estatuto da Corte Internacional de Justiça. Nova Iorque: Nações Unidas, Departamento de Informação Pública, s. d. 
Disponível em: <http://www.un.org/en/documents/charter/>, Acesso em: 30 de Outubro de 2013.

2015. Mapa do Sistema das Nações Unidas. Disponível em: <http://www.un.org/en/aboutun/structure/pdfs/UN_System_Chart_30June2015.pdf> Acesso em 6 de Agosto de 2015.

.A/59/565 Assembleia Geral. A more secure world: our shared responsibility. 2004.

(http://www.un.org/en/peacebuilding/pdf/historical/hlp_more_secure_world.p df) [20 de Agosto de 2014]

.A/47/277 An Agenda for Peace. 17 de Junho de 1992, <http://daccess-ddsy.un.org/doc/UNDOC/GEN/N92/259/61/PDF/N9225961.pdf?OpenElement>, Acesso em: 20 de Agosto de 2014.

.A/64/868 Review of the United Nations peacebuilding architecture. Disponível em:

<http://www.un.org/en/ga/search/view_doc.asp?symbol=A/64/868\&Lang=E> Acesso em: 11 de Fevereiro de 2015.

.A/RES/60/180 Resolução da Assembleia Geral. 30 de dezembro de 2005, (http://www.securitycouncilreport.org/atf/cf/\%7B65BFCF9B-6D27-4E9C8CD3-CF6E4FF96FF9\%7D/PBC\%20ARES60180.pdf), [15 de Outubro de 2013].

.PBC (2015). Country-Specific Configurations. Disponível em: <http://www.un.org/en/peacebuilding/countryconfig.shtml > Acesso em: 07 de Agosto de 2015

.PBSO (2015). Peacebuilding and the United Nations. <http://www.un.org/en/peacebuilding/pbso/pbun.shtml> Acesso em 6 de Agosto de 2015.

.S/RES/1645 Resolução do Conselho de Segurança, 20 de Dezembro de 2005, <http://www.unrol.org/files/N0565417.pdf> [5 de Outubro de 2013].

.S/RES/1646 (2005). Resolução do Conselho de Segurança. 20 de dezembro de 2005.

Disponível

em:

<http://www.un.org/en/ga/search/view_doc.asp?symbol=s/res/1646(2005) > Acesso em: 07 de Agosto de 2015

.WGLL (2010) Emerging Lessons and Practices in Peacebuilding, 2007-2009 Report of the Working Group on Lessons Learned of the Peacebuilding Commission. Maio 2010. $30 \quad$ p. $\quad$ Disponível em: http://www.un.org/en/peacebuilding/pdf/doc_wgll/wgll_report_english.pdf> Acesso em: 07 de Agosto de 2015

.WGLL (2015). Working Group On Lessons Learned. Disponível em: < http://www.un.org/en/peacebuilding/sm_lessonslearned.shtml> Acesso em: 07 de Agosto de 2015

NEVES, Gilda Motta Santos.Comissão das Nações Unidas para Consolidação da Paz: perspectiva brasileira. Brasília : FUNAG, 2009. 236 p.

PARIS, Roland (2004) At War's End: Building Peace After Civil Conflict. Cambridge: Cambridge University Press. 
PARIS, Roland (2009). Understanding the "coordination problem" in postwar statebuilding. In: PARIS, Roland; SISK, Timothy. The Dilemmas of Statebuilding: Confronting the Contradictions of Postwar Peace Operations. Nueva York, Routledge.

RICHMOND, Oliver (2007) The Transformation of Peace. New York: Palgrave Macmillan

RICHMOND, Oliver; FRANKS, Jason (2008) Liberal Peacebuilding in Timor Leste: The Emperor's New Clothes. International Peacekeeping, Vol.15, No.2, April 2008, pp.185-200.

RODRIGUES, Fernando Carlos Cavalcante Barros. Coming into life: the concept of peace building in the United Nations, from "An Agenda for Peace" to the Peace building Commission. Tese de Doutoramento em Relações Internacionais (Política Internacional e Resolução de Conflitos), apresentada à Faculdade de Economia da Universidade de Coimbra. Coimbra: 2013.

SCR (2013) The Security Council and the UN Peacebuilding Commission. Security Council Report. 18 de Abril de 2013. Disponível em: < http://www.securitycouncilreport.org/atf/cf/\%7B65BFCF9B-6D27-4E9C-8CD3CF6E4FF96FF9\%7D/special_research_report_1_pbc_2013.pdf> Acesso em: 07 de Agosto de 2015

SENDING, Ole Jacob. Why Peacebuilders Fail to Secure Ownership and be Sensitive to Context. Norwegian Institute of International Affairs. Security in Practice 12009. Disponível

em: <http://brage.bibsys.no/xmlui/bitstream/handle/11250/277766/3/SIP-1-WP755-Sending.pdf> Acesso em: 7 de Agosto de 2015.

STAMNES, Eli. Values, Context and Hybridity. How can the insights from the liberal peace critique literature be brought to bear on the practices of the UN Peacebuilding Architecture? Norwegian Institute of International Affairs. Centre for International Policy Studies, University of Ottawa. 2010.Disponível Em: http://cips.uottawa.ca/eng/documents/Stamnes.pdf> Acesso em: 07 de Agosto de 2015. 